\title{
New graduates' readiness for practice in Swaziland: An exploration of stakeholders' perspectives
}

\author{
Colile P. Dlamini ${ }^{1}$, Ntombifikile G. Mtshali ${ }^{2}$, Cynthia H. Dlamini ${ }^{1}$, Sotah Mahanya ${ }^{1}$, Thabile \\ Shabangu ${ }^{3}$, Zwelithini Tsabedze ${ }^{3}$
}

1. Department of General Nursing, Faculty of Health Sciences, University of Swaziland, Mbabane, Swaziland. 2. Teaching and Learning, College of Health Sciences, University of KwaZulu Natal, Durban, South Africa. 3. Mbabane Government Hospital, Mbabane, Swaziland.

Correspondence: Colile P. Dlamini. Address: D5 Gables, H126, Swaziland. Email: ccolile@yahoo.com

Received: November 20, 2013

Accepted: February 13, $2014 \quad$ Online Published: March 26, 2014

DOI : $10.5430 /$ jnep.v4n5p148

URL: http://dx.doi.org/10.5430/jnep.v4n5p148

\section{Abstract}

Background: Employers and educators of nurses expect that, upon graduation, they will have acquired a basic set of scientific knowledge, clinical skills and professional attitudes. In Swaziland, however, these expectations remain unmet.

Methods: We explored the perceptions of stakeholders in nursing education of how new graduates cope and perform at service entry and the factors influencing their clinical competence. From 31 purposively recruited participants, audio-recorded focus group discussions were held with registered nurses and semi-structured interviews with lecturers and nurse managers. Data were analyzed thematically.

Results: Results showed that although the graduates indicated their willingness to learn and become autonomous in their practice, stakeholders felt that most new graduates were not ready for practice upon graduation. Factors contributing to this discrepancy were associated with inadequate preparation and lack of support upon service entry.

Conclusions: Stakeholders' perceptions of the new graduates not being ready for practice call for the collaboration of academia, service and the regulatory body in establishing quality assurance mechanisms for clinical education and in providing structured support for new graduates at service entry to enhance easier and safer transition.

\section{Key words}

Recent graduate, Preparation-practice gap, Clinical practice environment, Nursing, Competency, Swaziland

\section{I ntroduction}

Practice readiness of New Graduates (NG) has been a concern for nursing education stakeholders for some time. Although the definition of this concept remains elusive ${ }^{[1,2]}$, being work ready has generally been defined according to the competencies that new graduates must attain upon completion of training. While the tenets of what constitutes competence or competency also remain debatable ${ }^{[3]}$, the attributes of a competent nurse graduate generally involve the ability to apply evidence to practice, work collaboratively with other health care professionals, and have critical decision-making and problem solving skills and mindfulness of professional ethics and value of patients ${ }^{[4]}$. In Swaziland, this expectation seems to remain unmet, with the public and nursing stakeholders questioning nursing education institutions about the perceived decline in the quality of nursing care that is being provided by the new graduates. 


\subsection{Context}

The kingdom of Swaziland is located in sub-Sahara Africa (SSA). Swaziland experiences the highest prevalence rate of HIV/AIDS in the world at 31\% among adults aged 18-49, and currently ranks as one of the highest in TB notification and related mortality ${ }^{[5]}$. The main actors in the health sector are nurses, who form more than $80 \%$ of the human resources for health ${ }^{[6]}$. Nurses in the kingdom confront many challenges as they battle with unfavourable working conditions, the high disease burden and poor remuneration, especially in the public sector ${ }^{[7]}$. These issues, among others, pose a threat to the country's health care system. Criticism abounds, and the sloppy nursing care and poor performance of recent graduates have become common news. These complaints have become especially resonant following the shift in nursing education that occurred more than a decade ago when the apprenticeship model of training by colleges was replaced with higher education.

Although the evolution of nursing education in Swaziland has been slow, the sounds of its critics have never been louder. Nursing in Swaziland is self-regulated by the Swaziland Nursing Council (SNC). There are currently two levels of registered nurses (RNs): the general nurse, who studies for three years to obtain a diploma certificate; and the graduate, who studies for five years to obtain a Bachelor of Nursing Science degree. To obtain the degree, however, students first need to study for the diploma and then add two more years of training. A new four-year generic BN program has been introduced, the first cohort of which will graduate in 2015.

Locally trained candidates who have graduated from the approved academic nursing program become licensed and do not have to take an entry to practice exam ${ }^{[8]}$. Because of this arrangement and because employers do not provide any form of intensive induction post-licensure, academic institutions are challenged to play their role in ensuring that their graduates are competent on graduation, since service expects the RN to efficiently and effectively deliver from the entry point.

\subsection{Literature}

International studies have demonstrated divergent findings regarding the competency of recent graduates ${ }^{[9-11]}$. In some studies, graduates reported that they felt unprepared for practice and described their experiences as frightening and traumatic. They said that they lacked self-confidence, especially with technical skills, leadership and decisionmaking ${ }^{[3,12,13]}$. Literature demonstrates that various stakeholders, especially educators and employers have different views of recent graduates' practice readiness ${ }^{[14,15]}$. In the United States, the Nurse Executive Centre conducted a survey to capture the perspectives of academia and industry about the new graduates' readiness for practice. Their findings showed that Deans were confident of their product, whilst employers were not happy about the quality of graduates produced. In this particular study, $89.9 \%$ of the Deans perceived new graduates as adequately prepared to provide safe and effective care, yet only $10.4 \%$ of hospital executives concurred. Such a difference could be contextual to where the education is grounded ${ }^{[14]}$, because globally, there is no uniformity or a mandatory system to safeguard the quality of undergraduate training ${ }^{[16]}$.

Levett-Jones and Lathlean ${ }^{[17]}$ suggested that graduating students attain clinical competency when their psychosocial needs for safety and security, belongingness and self-concept have been met. They asserted that the clinical placement experience often determines the success or failure of students in reaching competency; which they explained as "the need to be competent, confident, efficacious professional with a passion for and commitment to patient-centred care" ${ }^{[17]}$. Qualified staff and employers expect new graduates to 'hit the ground running' when they start service ${ }^{[18]}$, which can be unrealistic, as much depends on the socialization of the new graduate. Mooney ${ }^{[19]}$ believes that socialization is key to the transition phase, which is the period from when the new graduates enter into service until they are confident that they can practice autonomously or with minimal supervision. For most new graduates, this period lasts between at least six months to a year ${ }^{[13,20]}$. It is the time when new graduates leave the nest ${ }^{[21]}$ to join the flight, a time which could either strengthen or destroy them. 
Some studies demonstrate that new graduates who found themselves in settings which lacked support from staff viewed their transition as being 'thrown into the deep end ${ }^{[20]}$ or set out to fail ${ }^{[3,18]}$, while others viewed transition programs as their source of refuge, describing it as a time when they were able to 'shelter under the umbrella' in times of uncertainty before their confidence had been developed ${ }^{[22]}$. Rush found that formal programs resulted in retention and development of practical skills ${ }^{[23]}$. Literature shows a plethora of studies about new graduates' experiences, their level of competency, readiness for practice and the effects of transition programs, most of which were conducted in developed countries. There is paucity of similar studies in Africa, especially the SSA, yet in this region, nurses can be viewed as the glue that holds the health systems together.

\subsection{Study purpose}

Following the transition of nursing to higher education, there is no evidence of how the graduates of the university model cope in their new role after graduation and what factors influence their clinical proficiency. This study explored stakeholders' perceptions of the product of nursing education in order to identify areas that could be improved from both the academic and service settings. The aim was to provide evidence on the assumptions and views held by stakeholders about the product of nursing education in order to enhance student preparation and facilitate the transition of graduates as they develop into autonomous, competent and effective professionals who can provide safe and relevant nursing care. The research questions that were answered by this study were: how are the new graduates in terms of clinical proficiency and what factors could have contributed to their clinical proficiency?

\section{Methods}

\subsection{Participants}

Thirty-one participants participated in two focus groups discussions (FGDs). These included six nurse educators (NEs) from one university, six unit managers (UMs) from the health facility where students practice, four nurse leaders (NLs) from academic and service institutions and the Ministry of Health, two of whom served in the SNC, and 15 registered nurses (RNs) from the clinical practice setting, who worked in the units where general nursing students are allocated for clinical placement. Although RNs in Swaziland are expected to guide students during their clinical attachment in accordance with a directive of the nursing education and practice standards by the SNC, RNs are not trained to be clinical mentors or preceptors and it is commonly known that they do not always fulfil their obligations in this respect. Nurses who do support students are perceived as doing so out of the goodness of their hearts.

The criteria for inclusion in the study were that participants were registered nurses, involved in clinical education and willing to participate. These groups of stakeholders are believed to influence clinical education and practice.

\subsection{Design}

Using a qualitative approach, we explored the perceptions of nursing education stakeholders regarding the proficiency of new graduates from one university in Swaziland. As part of a four-phased action research project aimed at developing a clinical education model in Swaziland, this paper presents the initial phase of the first cycle, which was aimed at analyzing the clinical education context.

\subsection{Data collection and analysis}

Before the data collection process, we met as a research team and discussed how we were going to conduct the process. Two focus group discussions (FGDs) were conducted with registered nurses, one with seasoned staff and the other with new graduates (less than five years of experience). Each session lasted an average of 40 minutes. To ensure consistency, two researchers collected data, with the study coordinator facilitating all the discussions and another taking notes. Data were collected from educators, unit managers and nurse leaders through face to face semi-structured interviews, each 
taking an average of 25 minutes. All data collection sessions were audio-recorded with the participants' permisssion. Discussions were centred on how stakeholders viewed recent graduates in terms of clinical proficiency and factors that could influence their readiness to pratice upon graduation.

The analysis occurred concurrently with the data collection process, which allowed modification of data collected and the analysis process. Using constant comparison, data were analysed thematically. We listened to the mp3 audio-records several times, read through the transcripts line by line, coded the data, clustered the codes into themes and then into categories. To ensure trustworthiness, the mp3 files, transcripts and codes were kept as an audit trail. During data collection, the accuracy of data was checked on the spot at the end of each session through verification and during analysis, transcripts were verified through member checks. Three of us conducted the analysis and one researcher experienced in qualitative methods verified the themes and categories. We organised a reflective seminar where we presented the preliminary results to participants for their comments and corrections to ensure that their views had been accurately captured and reflected.

\subsection{Ethical consideration}

Since this study was part of a $\mathrm{PhD}$ research project, ethical clearance was attained from the University of KwaZulu-Natal Research Ethics Committee, protocol HSS/1312/011D. Further clearance and permission to conduct the study was attained from the Swaziland Ministry of Health Research Ethics Committee and from the relevant academic and health institutions. Individual participants gave informed consent to participate in this study and their ethical rights were respected. All data collection devices and transcripts were privy to the research team only and no names were used to identify participants. It was made clear to the participants that they did not have to respond to any question they felt uncomfortable with and that they were free to withdraw from the study at any time.

\section{Results}

The three guiding questions asked during data collection were: a) what are your views regarding the recent graduates in terms of their clinical proficiency; b) what factors could have influenced their competency; and c) how?

Stakeholders perceived that most new graduates were not ready for practice on licensure. From the data sources, clinical proficiency was defined as the ability to confidently and competently practice autonomously in clinical situations, applying scientific and practical knowledge in perfomance of clinical skills and demonstrating sound professional attitudes. Two categories emerged from the analysis: (i) at graduation and (ii) during preparation, with three and two themes respectively. Table1 illustrates the emergent themes and categories:

Table 1. Categories and themes

\begin{tabular}{lll}
\hline Categories & At Graduation & During preparation \\
\hline \multirow{2}{*}{ Themes } & Not ready for practice & No passion for nursing \\
& Comparing graduates & Devaluing of clinical practicum \\
& Support us & \\
\hline
\end{tabular}

\subsection{Category 1: At graduation}

After years of academic preparation, nurse graduates join service to practice, with the hope that they have been adequately prepared and are qualified to deal with any form of challenge or situation therein.

\subsubsection{Theme 1: Not ready for practice}

It emerged from the data that all the nurse groups who participated in the study shared the view that new graduate nurses were not ready for practice upon licensure. It is expected that upon graduation, nurses should have attained specific 
scientific knowledge, clinical skills and professional attitudes that will enable them to practice proficiently and autonomously. Participants felt that although a majority of the new graduates have attained adequate theoretical knowledge upon graduation, they lacked the clinical skills and professional attributes that are required for contemporary practice. Some of the excerpts from interviews were:

'...they are half cooked. They are shaky in terms of clinical practice; they have the theory, but are not grounded in clinical practice. They are not as proficient as we would have loved them to be, they cannot translate the acquired theory to clinical practice'. [sic] (NL3)

'They are not performing up to standard, they are lacking in terms of clinical skills, they are really wanting.' [sic] (NL2)

Some of the participants' expressions had emotional undertones, indicating that the subject on graduates' clinical competency was of concern to them.

"I don't want to criticise, but those that I've met are not competent. It's so painful to see this graduate who cannot even put up an IV line...they actually tell you that they cannot start the IV line!” [sic] (UM1)

"This is a depressing question... They are not performing up to standard; they lack completely in clinical practice...” (NE 3)

The new graduates expressed mixed feelings about their competency or proficiency. Some felt that they were competent, but lacked confidence to make decisions or perform technical skills, whilst others perceived themselves as having nothing to give:

"For the first few months, we lacked confidence, sometimes one may know what to do but be afraid to act; we need someone to affirm...I was not confident having to manage a unit by myself, and performing certain clinical procedures was not easy...” ((NG) 2)

"After graduation, I was allocated in the emergency and I was running around since I had no idea of what I was supposed to do. I could not wear the bars on my epaulets because the other nurses who were more experienced but had lesser qualifications were looking up to me when in fact I had nothing to give.” [sic] (NG 4)

Most of the managers expressed concern that newly graduated nurses need constant supervision and cannot be left in charge of a unit. It became apparent that the experienced nurses commonly used phrases such as 'qualified students' when referring to their newly qualified colleagues. New graduates are also often derogatorily referred to as "students in white", implying that it is unfitting that one who is 'not yet qualified' should be wearing the white uniform of registered nurses. Another cynical phrase commonly used in the clinical area is 'students with bleeding shoulders', a disparaging reference to the red epaulets worn by RNs. Some of the excerpts were:

"Even themselves, they do not feel comfortable to be left alone in the wards because they don't know what to do, and are not confident doing clinical procedures alone. They have more questions and some behave like students despite having qualified; they are students in white” [sic] (RN 5)

"It's embarrassing to be a student with bleeding shoulders, so they should try by all means not to find themselves put in such a situation.” (RN 2)

The nurse made this remark as a caution to current students who are supposedly not taking clinical practice seriously.

\subsubsection{Theme 2: Comparing graduates}

Most BN graduates had not had a break for practical work between the three year diploma and the two year degree and were therefore not regarded as 'true diplomates', a reference to those who had been trained in the apprenticeship model in nursing colleges. Although it was never said outright, some of the clinicians implied that the current graduates were not of 
the same standard as the diplomates, suggesting that at entry to service, diplomates had been much more competent than the current graduates.

"In our days, we were confident to leave any new diploma nurse in charge of the unit, but now, with these ones, ay, you cannot; you need to hang around as a sister.” [sic] (UM 5)

Seniority ranking among nurses is based on qualification and promotion. Paradoxically, although the new graduate is perceived as being junior in terms of being inexperienced and new in the unit, they are senior in terms of qualification and are therefore expected to be more knowledgeable, technically skillful and confident about clinical problem solving and decision making. However, if the nurses in practice continually criticize the new graduates as having no experience and nothing to offer, it could intensify their feelings of helplessness and inadequacy. Unreasonably high expectations combined with poor support and seasoned staff's habit of comparing them with diploma nurses and nurse assistants create tension in the workplace.

'You get surprised when you see them, for example one used a pair of scissors to cut a blood unit pack... and the NA (Nurse assistants) around were watching. She was embarrassed to ask how this was done; yet she is senior now, fresh from school.” [sic] (RN 3)

\subsubsection{Theme 3: Support us}

The new graduates acknowledged their inadequacy and pleaded for support upon entry to service. Currently, there is no program aimed at equipping or even orienting new graduates as they enter into service. Recent graduates mentioned that they are left to manage units as if they are being tested rather than welcomed, oriented, supported and even accepted as new team members. They felt that it was essential to have some support from the experienced staff in the first few months of service to help them gain confidence and become familiar with the working environment. Upon recruitment, the transition of new graduates could be enhanced if they were recognised as novice members of the team and received support and understanding from the experienced staff.

"We need support when we get to work; we are willing to learn as much as we can so to function independently". (NG 5)

"There has to be courses designed to introduce us to the work environment, because when we get here, we are left to manage the unit as if we are being tested. We need these old guys to understand that we are fresh from school, some things we may have never practiced before and they know this...they also went through the same process, didn’t they?'. (NG 1)

“....at entry point, we need serious supervision...now that I'm hired, for me to adapt to this new environment, I need another nurse to take me through”. (NG 2)

\subsection{Category 2: During preparation}

The results revealed that the new graduates' lack of readiness for practice evolved mainly around the preparation of nurses and the lack of support on recruitment. It became apparent that there were discrepancies in the preparation of this generation of nurses. The nursing education system has limitations in terms of student preparation, and post training, the service sector fails to support and adequately induct the recent graduate. During preparation, students' and systems' contributors to the descrepency emerged as: no passion for nursing and devaluing of the clinical practice component, respectively.

\subsubsection{Theme 1: No passion for nursing}

Although passion could not be measured in this study, there was a strong and shared perception by all the stakeholders that the current generation of nurses, especially the BNs, do not enjoy the practical side of nursing and do not regard it as a lifelong vocation. It is believed that the profession is used as a gateway to other professions which have more prestige and offer lucrative remuneration. The general assumption that participants held was that the majority of the new generation 
nurses in Swaziland have no real passion for nursing and see it simply as a stepping stone. They therefore pay little attention to the practical aspect of their studies and, on deployment, show no enthusiasm in the clinical setting. Some excerpts expressed by participants:

"We have come up with the notion that they are lazy, you'll always find them in the nurses' station...they are not enjoying the nursing...They are not motivated. With the other Sisters' (unit managers), we have come to a conclusion that these new nurses do not like the bedside nursing, they run away to NGO's (non-governmental organization). My observation is that they are not interested in this profession.” (UM 1)

“These new nurses see nursing as a passage to medicine or to NGO's, they don't like the bedside nursing, or the profession. I'm afraid we are just wasting our time with them here. They don't stay.” (NL 3).

"If there was someone or something that could stir up the love for nursing...the passion in some of us." (NG 2)

\subsubsection{Theme 2: Devaluing of clinical practice component during training}

It emerged from the findings that during training, more attention is given to the classroom component than the clinical practice component. Participants assumed that this could be a reason why students do not take the clinical component seriously and thus fail to attain the necessary standards. Furthermore, it was found that whilst they were students, some of the graduates would deliberately miss clinical practice to pursue non-clinical assignments or study for tests. Participants revealed that during clinical practice, students would either leave the shift early or not show up at all. It seemed that they knew from experience that there would be no repercussions for missing clinical practice and, more significantly, the greater part of the assessment grades were generated from the theory component. This limitation has been partly addressed by the university by offering a four years generic program. Some expressions by clinicians were:

"They think nursing is all about passing the theory, they cheated the practical; and now it's catching up with them.” (UM 4)

"The value of clinicals is not taken seriously here, students would come and go as they please. When we received a list (clinical placement schedule) that we will have four students, only one would turn up and she will also leave after medical rounds.” (RN 5)

One of the recent graduates reflected on his experience during training, admitting that he and his colleagues avoided attending clinical practice.

"When we were supposed to write a test on a Wednesday for example, and we had clinicals on a Monday and Tuesday, I would go to the ward just for a face presentation and after medical rounds I'll leave, never to come back, anyway no one monitored.” (NG 4)

\section{Discussion}

A consensus was reached among participants on their perception that new graduates were not work ready ${ }^{\text {[24] }}$. This differs from the findings by the Nursing Executive Centre ${ }^{[15]}$ where disparate views of Deans and hospital executive were reported. Although derogatory phrases are used to refer to new graduates and seasoned staff expect them to 'hit the ground running, ${ }^{[25]}$ right after graduation, literature shows that most new graduates from the various types of pre-licensure programs are inadequately prepared for practice and lack the essential clinical knowledge and practice skill competencies ${ }^{[11]}$. O'shea and Kelly found that new graduates had no problem performing 'routine clinical procedures' like dressings, but had challenges with the non-routine clinical skills, such as nasogastric (NG) tube passing, indicating their lack of exposure during training. However, in this study most of the complaints by participants included venipuncture, IV therapy and IM injections, which are regarded as routine in this context. 
The inadequacy of student preparation especially with clinical skills has been a concern in literature for a long time and similar to this study results, Charnley ${ }^{[26]}$ associated such inadequacy with curricula emphasis on theory rather than on hands-on patient care. After all, nurses gain clinical competency when exposed to the real practice situations with actual patients. Hence, Hancock ${ }^{[27]}$ suggests that at least $50 \%$ of the nursing curriculum should include clinical practice. Of concern in this study is that students deliberately miss clinical practicum and therefore do not fulfil the stipulated clinical time. Furthermore, there is no entry to practice exam that could determine if they are competent or work ready given their preparation inadequacies. Literature regarding cheating clinical time is scarce and it can therefore be assumed that this might not be a problem elsewhere and thus calls for the local nursing faculty to work collaboratively with clinical staff to establish a quality assurance mechanism for clinical education.

It is also of concern that after graduation, no provision is made to support the graduate nurses in their new role. Graduates expressed feelings of inadequacy and lack of confidence during the first months of service, which develops with time $^{[12,13]}$. In most contexts, new graduates are mentored, but in Swaziland, no form of support exists. Because of the limited support received by graduates in Africa, the World Health Organization (WHO) suggested classroom: clinical ratio for pre-registration programs in 2000 to be $1: 3$ or $1: 4^{[28]}$. The challenge exists when there is no system in place to monitor the quality of clinical placements and the students are not self-directed or motivated to value clinical placements.

The context where learning occurs is critical in the development and nurturing of students. The absence of appropriate structures to promote positive engagement during and after training is a concern to be addressed by the academic, service and regulatory agencies. The context includes both the physical and social environments within which nurses are trained and practice after graduation. To compensate for preparation limitations, most nursing bodies require that graduates undergo a transitory program before licensure, such as nurse residency or internship programs ${ }^{[13,29]}$ preparing the nurse before leaving the nest ${ }^{[21]}$. Graduate programs, such as preceptorship ${ }^{[2,22]}$ and remunerated community service ${ }^{[30]}$ which are designed to socialize graduates into their new roles and environments, could be valuable for professional maturity and patient safety ${ }^{[31]}$. Such programs provide guidance through hands-on nursing care and allow the graduate time to learn and fit in without feeling insecure or inadequate. Developing countries like Swaziland that do not have such arrangements for their students and new graduates could benefit from the introduction of such programs. Validated benefits include heightened confidence levels as freedom to plan and implement nursing care is increased whilst the fear of error or jeopardizing patients' safety subsides ${ }^{[32]}$, increased job satisfaction ${ }^{[33]}$, high retention rates among new graduates and huge savings for employers ${ }^{[34]}$.

Although the seasoned staff often criticize the new graduates with regard to how they behave and how their values are inconsistent with the profession ${ }^{[35]}$, it is important to remember that the times, conditions, and academic and practice contexts are dynamic. The contest between diploma and degree nurses has been expressed as not only shaped by the generational differences, but also by the different academic preparation of these two groups ${ }^{[14]}$. The results of this study are consistent with literature as the diploma nurses believed that they competently "walked into practice" ${ }^{[14]}$. It was apparent in this study that participants who had been trained in the apprenticeship model and qualified with a diploma perceived that they had been 'ready' and could work autonomously upon graduation, whilst the BN graduates seem to struggle as they enter service and fail to meet their expectations. However, the findings of this study also revealed that the staff have unrealistic expectations and are not supportive of the new graduates when they enter service as well as being very critical of them, which creates tension in the workplace and engenders poor working relations. In contrast to O'shea and Kelly's study, where new graduates were encouraged to check with others till they felt confident ${ }^{[12]}$, this study showed that graduates recoil from seeking help as are being derogatorily labelled as 'students in white', 'students with bleeding shoulders' and 'qualified students' by the more experienced members of staff. This culture is disappointing, as literature on lived experiences of new graduates, particularly in their first year, shows that socialization during transition could have major implications not only to the nurse, but also to the client, the health system and the public at large ${ }^{[19,21]}$, and can be a source of moral distress ${ }^{[36]}$ and attrition. 
In an economically constrained society with very limited opportunities, choice of career is a privilege. The scarcity of bursaries and sponsorship for higher education, the high unemployment rate of more than $40 \%{ }^{[37]}$ and the general socioeconomic status of the country affect people's career choices. Stakeholders explained that many of those who are currently joining the nursing profession see nursing as a transient career and described them as 'lacking passion for nursing' or 'having no love for the sick'. The Oxford American dictionary defines passion as an intense desire or enthusiasm for something. It can be assumed that lack of enthusiasm among new nurses may indicate that the majority of the next generation of nurses in Swaziland do not have their hearts in nursing, thus threatening its ability to thrive.

New graduates have a major role to play in not only replacing the older generation of nurses, but essentially guaranteeing the continuance of the profession ${ }^{[38]}$. Watson believes that nursing is a sacred science and spiritual practice, thus, as nurses, our passion and drive for this practice is invigorated and sustained in the compassionate care we devote to our clients ${ }^{[39]}$. Nursing is caring ${ }^{[40,41]}$ and the provision of nursing devoid of 'care' may be interpreted as merely a ritualistic performance of medical tasks. Studies have shown that nursing is viewed as an unpleasant job with a lot of distress, hence both passion and professional attitude are essential to coping and providing quality care ${ }^{[31]}$. Interestingly, Davis ${ }^{[42]}$ posted a blog to student nurses asking if they have passion for nursing. From the arguments, a number of students mentioned that they love working with people and find it fulfilling, but are not passionate about nursing. Most of the blog followers indicated that they are in the profession because of the security that nursing has to offer.

\section{Conclusion and recommendations}

A majority of new graduates in Swaziland were generally regarded as not ready for practice upon graduation and this was attributed to both academic and service factors that have widened the preparation-practice gap. Therefore, we recommend that the regulatory body together with the academic and service institutions collaborate and collegially develop and implement clinical education and practice quality assurance instruments, policies and guidelines to bridge the preparation-practice gap. Focus on developing a clinical education and supervision framework which will employ innovative learning approaches to promote quality in preparation and safe transition of graduates into service is necessary. Additionally, these agencies need to collaboratively study and correct the issues that demotivate students from attending clinical practice. We suggest that clinical learning environments be well organized and equipped to adequately prepare nurses and support students during placements. Furthermore, new graduates require structured support in terms of induction through residency or internship programs by employers to allow a smooth and safe transition into their new role. We recommend that research to evaluate the competence of nurse graduates is necessary to validate the perceptions of stakeholders, and another study that will measure students' interest in nursing be conducted so that appropriate measures can be taken to guide and support students.

\section{Acknowledgement}

This project was partially funded by the African Doctoral Dissertation Research Fellowship offered by the African Population and Health Research Centre (APHRC) in partnership with the International Development Centre (IDRC).

\section{References}

[1] Wolff AC, Regan S, Pesut B, Black J. Ready for what? An Exploration of the Meaning of New Graduate Nurses' Readiness for Practice. Intl J of Nurs Edu Scholarship. 2010; 7(1): 1-14. PMid:20196766 http://dx.doi.org/10.2202/1548-923X.1827

[2] Romyn DM, Linton N, Giblin C, Hendrickson B, Limacher LH, Murray C, et al. Successful transition of the new graduate nurse. Intl J Nurs Edu Scholarship. 2009; 6(1).

[3] Hartigan I, Murphy S, Flynn AV, Walshe N. Acute nursing episodes which challenge graduate’s competence: Perceptions of registered nurses. Nurs Edu Today. 2010; 10: 291-7. PMid:20167537 http://dx.doi.org/10.1016/j.nepr.2010.01.005

[4] Hegarty J, Walsh E, Condon C, Sweeney J. The Undergraduate Education of Nurses: Looking to the Future. Intl J of Nurs Edu Scholarship 2009; 6(1):1-11. PMid:19572833 http://dx.doi.org/10.2202/1548-923X.1684 
[5] Burger S. First Findings Released from Swaziland HIV Incidence Measurement Survey. Columbia: Mailman School of Public Health, 2012.

[6] Ministry of Health and Social Welfare (MOHSW). National Health Sector Strategic Plan 2008-2013. Mbabane: Swaziland Government; 2009.

[7] Kober K, van Damme W. Public sector nurses in Swaziland: can the downturn be reversed? Human Resource for Health. 2006; 4:13 (http://www.human-resources-health.com/content/4/1/13); Accessed 12.09.2013

[8] McCarthy CF, Voss J, Verani AR, Vidot P, Salmon ME, Riley P. Nursing and midwifery regulation and HIV scale-up: establishing a baseline in east, central and southern Africa. J Intl AIDS Society. 2013; 16: 18051. PMid:23531276 http://dx.doi.org/10.7448/IAS.16.1.18051

[9] Berkow S, Virkstis K, Stewart J, Conway L. Assessing new graduate nurse performance. Nurse Educator. 2009 ; 34 : 17-22. PMid:19104340 http://dx.doi.org/10.1097/01.NNE.0000343405.90362.15

[10] Safadi R, Jaradeh M, Bandak A, Froelicher E. Competence assessment of nursing graduates of Jordanian universities. Nurs and H Sci. 2010; 12: 147-54. PMid:20602685 http://dx.doi.org/10.1111/j.1442-2018.2009.00507.x

[11] Oermann MH, Poole-Dawkins K, Alvarez MT, Foster BB, O’Sullivan R. Managers' Perspectives of New Graduates of Accelerated Nursing Programs: How Do They Compare With Other Graduates? J Cont Edu Nurs. 2010; 41: 394-400. PMid:20540465 http://dx.doi.org/10.3928/00220124-20100601-01

[12] O'Shea M, Kelly B. The lived experiences of newly qualified nurses on clinical placement during the first six months following registration in the Republic of Ireland. J Clin Nurs. 2007; 16: 1534-42. PMid:17655542 http://dx.doi.org/10.1111/j.1365-2702.2006.01794.x

[13] Zinsmeister LB, Schafer D. The exploration of the lived experience of the graduate nurse making the transition to registered nurse during the first year of practice. J Nurses Staff Dev. 2009; 25: 28-34. PMid:19182555 http://dx.doi.org/10.1097/NND.0b013e318194b58c

[14] Wolff AC, Pesut B, Regan S. New graduate nurse practice readiness: Perspectives on the context shaping our understanding and expectations. Nurs Edu Today. 2010; 30: 187-91. PMid:19699561 http://dx.doi.org/10.1016/j.nedt.2009.07.011

[15] Stewart J, Conway L, Virkstis K, Berkow S, Avery S. Bridging the Preparation-Practice Gap. Volume I: Quantifying New Graduate Nurse Improvement Needs. Washington D.C.: Advisory Board Company; 2008.

[16] Bradshaw A, Merriman C. Nursing competence 10 years on: fit for practice and purpose yet? J Clin Nurs. 2008; 17: 1263-9. PMid:18416778 http://dx.doi.org/10.1111/j.1365-2702.2007.02243.x

[17] Levett-Jones T, Lathlean J. The Ascent to Competence conceptual framework: an outcome of a study of belongingness. J Clin Nurs. 2009; 18: 2870-9. PMid:19220619 http://dx.doi.org/10.1111/j.1365-2702.2008.02593.x

[18] Phillips C, Kenny A, Esterman A, Smith C. A. Secondary data analysis examining the needs of graduate nurses in their transition to a new role. Nurs Edu Today, in press.

[19] Mooney M. Professional socialization: The key to survival as a newly qualified nurse. Intl J Nurs Prac. 2007 ; 13 : 75-80. PMid:17394514 http://dx.doi.org/10.1111/j.1440-172X.2007.00617.x

[20] Kelly J, Ahern K. Preparing nurses for practice: A phenomenological study of the new graduate in Australia. J Clin Nurs. 2008; 18: 910-8. PMid:18665878

[21] Morrow S. New graduate transitions: leaving the nest, joining the flight. J Nurs Management. 2009; $17: 278-87$. http://dx.doi.org/10.1111/j.1365-2834.2008.00886.x

[22] Newton JM, Mackeena L. The transitional journey through the graduate year: A focus group study. Intl J Nurs Studies. 2007; 44: 1231-7. PMid:16867302 http://dx.doi.org/10.1016/j.ijnurstu.2006.05.017

[23] Rush KL, Adamack M, Gordon J, Lilly M, Janke R. Best practices of formal new graduate nurse transition programs: An integrative review. Intl J Nurs Studies. 2013; 50: 345-56. PMid:22795800 http://dx.doi.org/10.1016/j.ijnurstu.2012.06.009

[24] Baldwin A, Bentley K, Langtree T, Mills J. Achieving graduate outcomes in undergraduate nursing education: following the Yellow Brick Road. Nurs Edu Prac in press. PMid:23886647

[25] Brans L. "Hit the ground running". The graduate year: issues for the nursing profession. Royal College of Nursing Conference. Melbourne: Australia1997.

[26] Charnley E. Occupational stress in the newly qualified staff nurse. Nurs Std. 1999; 13: 33-6.

[27] Hancock PK. Nurse migration: the effects on nursing education. Intl Nurs Review. 2008; 55: 258-64. PMid:19522940 http://dx.doi.org/10.1111/j.1466-7657.2008.00637.x

[28] Uys LR. Developing a macro-curriculum. In: Uys LR, Gwele NS, eds. Curriculum development in nursing: Process and innovation London: Routledge. 2005; 45-67.

[29] Messmer PR, Bragg J, Williams PD. Support Pragrams for New Graduates in Pediatric Nursing. J Cont Edu Nurs. 2011; 42: 183-92. PMid:21462909 http://dx.doi.org/10.3928/00220124-20110324-05 
[30] SANC. South African Nursing Council Community Service. Community Service. Pretoria: South African Nursing Council; 2005.

[31] Patterson C, Curtis J, Reid A. Skills, knowledge, and attitudes expected of a newly-graduated mental health nurse in an inpatient setting. Intl J Mental H Nurs. 2008; 17: 410-8. PMid:19128288 http://dx.doi.org/10.1111/j.1447-0349.2008.00572.x

[32] Saintsing D, Gibson LM, Pennington AW. The novice nurse and clinical decision-making: how to avoid errors. J Nurs Management. 2011; 19: 354-9. PMid:21507106 http://dx.doi.org/10.1111/j.1365-2834.2011.01248.x

[33] Halfer D, Graf E, Sullivan C. The organizational impact of a new graduate paediatric nurse mentoring programme. Nurs Economics. 2008; 26: 243-50. PMid:18777973

[34] Hillman L, Foster RR. The impact of a nursing transition programme on retention and cost savings. J Nurs Management. 2011; 19: 50-6. PMid:21223405 http://dx.doi.org/10.1111/j.1365-2834.2010.01187.x

[35] LeDuc K, Kotzer AM. Bridging the gap: A Comparison of the Professional Nursing Values of Students, New Graduates, and Seasoned Professionals. Nurs Edu Perspective. 2009; 30: 284.

[36] Kelly B. Preserving moral integrity: a follow up study with new graduate nurses. J Adv Nurs. 1998; 28: 1134-45. PMid:9840887 http://dx.doi.org/10.1046/j.1365-2648.1998.00810.x

[37] Central Inteligence Agency (CIA). The World Factbook: Africa: Swaziland. CIA; 2013. Available from: https://www.cia.gov/library/publications/the-world-factbook/geos/wz.html

[38] Winfield C, Melo K, Myrick F. Meeting the challenge of new graduate role transition: clinical nurse educators leading the change. J for Nurs in Staff Dev. 2009; 25: 7-13. PMid:19346825 http://dx.doi.org/10.1097/NND.0b013e31819c76a3

[39] Watson J. Private Psalms: A Healing Mantra and Meditation Watson Caring Science Institute and International Caritus Consortium 2013.

[40] Watson J. Nursing: Human science and human care: A theory of nursing London: Jones \& Bartlett Publisher; 1999.

[41] Boykin A, Schoenhofer S. Caring in nursing: Analysis of extent theory. Nurs Sci Quarterly. 1990; 3: 149-55. http://dx.doi.org/10.1177/089431849000300406

[42] Davis MA. Do you have passion for nursing? allnursescom: allnurses; 2012. 